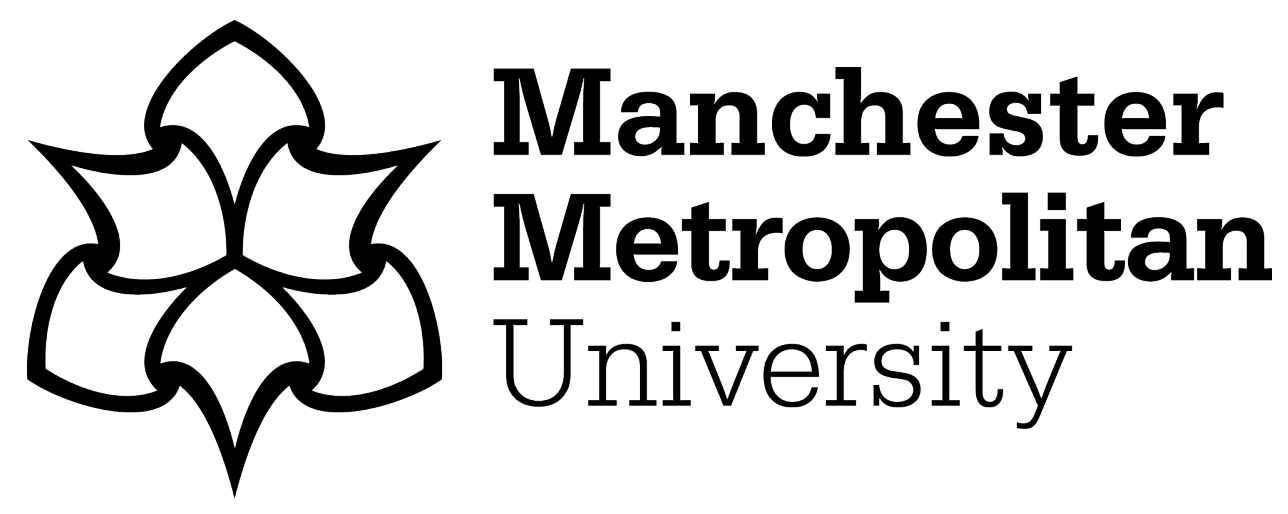

Stronach, lan, Corbin, Brian, McNamara, Olwen, Stark, Sheila and Warne, Tony (2002) Towards an uncertain politics of professionalism: teacher and nurse identities in flux. Journal of Education Policy, 17 (1). pp. 109-138. ISSN 0268-0939

Downloaded from: https://e-space.mmu.ac.uk/1795/

Version: Accepted Version

Publisher: Taylor \& Francis

DOI: https://doi.org/10.1080/02680930110100081

Usage rights: Creative Commons: Attribution-Noncommercial 4.0

Please cite the published version 


\section{Towards an uncertain politics of professionalism: teacher and nurse identities in flux}

'Few professionals talk as much about being professionals as those whose professional stature is in doubt.' (F. Katz, in A. Etzioni The semi-professions and their organisation. Teachers, nurses, social workers 1969.)

Our first purpose is to look at the epistemological, methodological and narrative strategies whereby 'professionalism' is currently conceptualised. We will try to show that the professional - as 'teacher' or 'nurse' - is an indefensibly unitary construct. There is no such thing as 'a teacher', and the notion of 'nurses' or 'teachers' is already too much of a generalisation. Similarly, we will hope to complicate the nature of 'professionalism', arguing that the analytical moves by which professionals are typified, staged, and judged betray a rather simple moral bias, chopping good from bad in unhelpfully crude ways.

Rejecting the somewhat static apparatus of types, stages and conditions that has generally been brought to bear on professional work, we propose a different reading of the professional as caught between what we will call an 'economy of performance' (manifestations broadly of the audit culture) and various 'ecologies of practice' (professional dispositions and commitments individually and collectively engendered)

Our intention is not to set up yet another analytical/moral polarity, but to look at the question of the professional self and its disparate allegiances as a series of contradictions and dilemmas that frame the identity of the professional as an implementer of policy. As a result, we claim that the question of 'professionalism' is bound up in the discursive dynamics of professionals attempting to address or redress the dilemmas (etc) of the job. Empirically we will seek to justify this account of the professional condition by looking both at teacher and nurse data. Our argument will be that the professional self that we wish to consider (there may be others) is a possible precipitate of these disjunctions. Such a position draws on and modifies recent thinking about 'selves' and 'identities' in anthropology:

'The self, then, is an instance superordinate to (though not detached from) the plurality of identities.' (Sokefeld 1999: 424)

We would prefer to say that the professional self currently mobilises discrepant identities that raise it as a problem for itself. In the case of the nurse and the teacher, we see that professional self as having an inherently problematic status (as the initial quotation in this paper suggests). This provokes professional 'selfwork' (Stronach and MacLure 1997: 135) as a discursive dynamics which may be resolved or dissolved dialectically in relation to the future, deconstructively in relation to the past, or reflexively in the present. These 'cross-cutting identities', by no means necessarily a postmodern phenomenon (Gluckman 1963), and the productive nature of selfconflicted belief, in turn, raise more general questions about the contemporary relation of 'self', 'identity' and 'professionalism' within what has been called the 'audit culture.' (Power 1994, Strathern 2000b)

Goodbye Mr Chips and you too, Nurse Ratchet.

The first argument we wish to advance is that the 'professional' is a construct born of methodological reduction, rhetorical inflation, and universalist excess. First, the paradox of a reduction that is also an inflation. In the literature, the professional is constructed very much as an emblematic figure. He or she is an expression of the 
zeitgeist, a 'Cartesianism' (Bowers and Flinders 1990: 12). Sometimes a heroine of Mills and Boon proportions: '[t]o love teaching is to give of yourself in a way that can be so tenderly vulnerable' (Liston 2000: 92). Often a victim: '..less and less planners of their own destiny and more and more deliverers of prescriptions written by others' (Goodson 2000: 14). But usually and enduringly the notion of the 'professional' has expressed a kind of over-investment in the professional as agent for good in society:

'...the growth of professionalism is one of the hopeful features of the time. The approach to problems of social conduct and social policy under the guidance of a professional tradition raises the ethical standard and widens the social outlook.' (Carr-Saunders, 1928, in Vollmer and Mills 1966: 9)

'The professional is motivated by service to the community rather than by the anticipation of an immediate material reward; altruistic values predominate over egoistic inclinations.' (Turner 1993: 14)

Professionals, then, are always much more and much less than themselves.

Methodologically the professional is set in this paradoxical motion by a simple polarity that goes by many names. Sometimes, as above, it is the fiduciary claim versus self-interest (Baver 1996: 23; Lyons and Mehta 1997). Other times, the professional is the 'key' to the 'ongoing contestation between state control and professional autonomy' (Helsby 2000: 93; see also Giri 2000: 174). Or the polarity may be established between the practical and the 'technical' (Smith 1999; Galton et al 1999: 189), or the traditional and the progressive, the holistic and the fragmented (Chinn and Jacobs 1987; Kirby 1995; Hargreaves and Goodson 1996). And, of course, a distinction between professional work as 'art' or as 'science' is commonplace (Wragg 1993; Smith 1981; Friedson 1983; Sarvimaki 1988). Nor indeed are these polarities a relatively recent phenomenon. In 1932, Waller was already writing in his pioneering study The Sociology of Teaching that 'the school must stop trying to become a machine and strive to realise its destiny as a social organism' (Waller 1932: 450). Arguing for education via 'participation in activities' (ibid.: 451), he concluded that '[i]t was obvious that the teacher must be free in his teaching..' (ibid.: 455). Yet the nurse or teacher 'as machine' is precisely the contemporary objective of current UK policy initiatives, as the apeing of High Reliability Organisations in schools (Reynolds 1998) and the drive towards evidencebased nursing and teaching practice indicate (Hargreaves 1996; Aikens M P 1997; Rolfe 1998). Most recently, the professional has been cast in the struggle between the audit culture and 'collective values and lateral solidarities' (Shore and Wright 2000: 77). Her anticipated demise in that context is held to be a matter of profound importance:

'...not so much a passing fashion as the expression of a much more permanent and profound system of governmentality that is radically transforming all areas of working life.' (ibid.: 79)

'...the shift, in anthropological ethics, from professionalism to audit is yet another instance of the swing of the liberal pendulum from a romantic primacy of the ethical to a utilitarian primacy of the economic.' (Pels 2000: 148)

We could go on, but this aspect of the picture is clear. Whether cast as a poetic, philosophical or political figure, the professional is constructed emblematically, as standing for much more than the 'semi-professional' that Etzioni prosaically identified. Methodologically, this is accomplished by simple analytical polarities that double as 
morality and destiny. As a result the professional is moralised both by being 'reduced' to a singular meaning and emplotment, and simultaneously inflated to improbable symbolic importance. Such a fate should not surprise us since the professional constructed in the literature is the alter ego of the author, who after all is almost always a professional working professionally to construct 'the professional' - and unlikely to put in a bad word for himself.

'Professionals' are not just set in motion between simple polarities. They are also systematically pinned down in terms of different types of knowledge (Eraut 1994; Rutty 1998), stages of development (Benner 1984; Huberman 1993), and typologies of role, such as the 'extended' versus the 'restricted' (Hoyle 1980; more recently Haughey 1996, Woods et al 1997; Ohlen and Segesten 1998). Similarly, there are held to be 'cosmopolitan' versus 'local' orientations (Gouldner 1957), or 'entreprenuerial' versus the 'led' (Redman 1997: 32). Equally, their performances are evaluated in terms of styles of working (Galton et al 1999; Haughey et al 1996). Naturally, these various characterisations and emplotments imply different sorts of denouement, and professionals are regularly consigned to, threatened with, or rescued from, 'proletarianisation' (Hargreaves 1994; Murphy 1990; Turner 1993; Ginsburg 1996), 'bureaucratisation' (Murphy 1990: 75),'intensification' (Galton et al.1999; Bell 1995: 17; Campbell and Neill 1994), and 'deprofessionalization' (Parkin 1995). The story of the harassed professional, then, is a familiar one, and so too are the narratives of redemption, whereby 'substantive selves' and 'core moral purposes' are preserved (Day 2000: 127; see also Keogh's 'altruism', 1997) via ethical codes and professional regulation. As Pels rather tartly notes:

'Having an ethical code is a necessity in the folk epistemology of professionalism.' (Pels 1999: 102)

Indeed, narratives of professional redemption are almost compulsory, at least for educational researchers. Even where theorists adopt the language and perspectives of Foucault (not an automatic choice for the pro-professional team), the professional must be rescued from the iron cage of the classroom or the ward. Out of surveillance, governmentality and so on emerges the 'authentic' teacher, in a rather mysterious rebirth (Ball 1999: 14), or the holistic nurse as 'productive professional' (Leddy and Pepper 1998: 112). In a similar sort of methodological rescue, Goodson separates the 'voice' of the teacher from the 'genealogy of context'(Goodson 2000: 22) vaguely connecting the two notions via a 'trading point'. Elsewhere in his argument, these 'intertextual' and 'intercontextual' (ibid.: 24) liaisons are invoked rather than argued, and so it is impossible to see how the subversive aspects of genealogy might treat with the 'authentic' words of the professional. Methodologically, Goodson has his cake and eats it, while reassuring the cake that its 'voice' will be safe in his mouth.

Finally, there is the charge of 'universalist excess' written into the very definition of the professional. As Turner sees it: '[p]rofessional culture has institutionalized universalistic standards of service delivery, regardless of the personal characteristics of the client which are irrelevant to the professional relationship' (Turner 1993: 14). Both teaching and nursing cultures express this universalism in a growing tendency to give national or even international expression to definitive lists of competencies. Universal consensus is projected as a permanently emerging but somehow never quite realised achievement, as in Day's recent invocation of the 'emerging international consensus' concerning the nature of teacher professionalism (Day 2000: 116). These are held to define the 'universal nurse' (Stark et al 2000; see also ENB 1999), the generic health worker, or the nationally specified 'competent teacher' (Stronach et al 1994). For example, the ENB has recently called for 'core 
competencies' to be established as 'part of a wider recognition among a range of professions of the need for greater specificity and national agreement regarding [necessary] skills, knowledge and attitudes...' (ENB 1999: 7.7). It is also clear that this drive towards universalism is led by policy-makers rather than professionals. The Department of Health 'will in future take more direct responsibility for the shape and direction of nurse and midwife education' (1999: 4.13). The English Department for Education and Employment (DfEE), of course, long since seized such an extraprofessional control.

The literature therefore tends to characterize 'professionalism' through methodological reduction, rhetorical inflation and universalizing excesses regarding the definition, project, and typologizing of the 'professional'. In effect, these research strategies generalise in order to categorise (by type or stage), and generalise again in order to construct particular 'truths'(eg the 'compliant technician') from singular facts, exercising a double erasure of difference which is acknowledged only in a neglected trail of caveats and qualifications. The result is one well-noted in anthropology - the emergence of the Collective Individual, in this case in the form of 'The Teacher' and 'The Nurse' rather than 'The Nuer'(Neiburg and Goldman 1998) . In the case of nursing, gender strengthens such unilateral readings, since nursing has historically been seen as a female profession (Dingwall and Mclntosh 1978; Strasen 1992; Breinlinger and Kelly 1994; Rutty 1998). And the more confident such abstractions appear, the more the author disappears behind a rhetoric of generalised certainty. We do not argue that such double-and-quit strategies are not commonsensical (they are the very stuff of stereotyping), but suggest that other intellectual tactics may provide more interesting and useful perspectives on 'the professional', 'professionalism' and the nature of professional performances. In particular, we would argue that the Collective Professional obscures the power/knowledge aspects of 'official' or officially sponsored educational discourses, as well as redrawing particularity as a 'locality' largely derived from global effects.

Humpty Dumpty as a professional 'model'; had a Great Fall; shame about the King's men etc.

We turn now to an attempt to complicate the notion of professionalism.

In an interesting discussion of ethical conduct, Dawson argues that professional virtue has at least two versions. The first is Aristotelian, based on the notion of the virtuous person. That is the 'inside out' version (Dawson 1994: 147). Inside-out ethics may be necessary in so far as 'a code of practice can never be rich enough to provide guidance in all situations, perhaps because there are so many ethical factors to be taken into account' (ibid.: 148). It can never be more than 'a type of shorthand'(ibid.: 152).The other version is 'outside in' where virtue is consequent to following prior principles regarding belief or conduct: '[o]n this view, making a decision about ethical conduct is merely a process of following the correct rule' (ibid.: 147). He then arrives at an interesting paradox: that ethical codes may be unethical in that they serve to 'minimize the responsibility of the professional for his or her actions' (ibid.: 153). Applying this perspective more generally to professionalism, we might infer from Dawson an educational model of professionalism since he posits a view of the 'moral agent as always responsive to the situation, of perpetually learning.' (ibid.: 153).

This relation between inside-out and outside-in professionalism offers a provocative expression of the dilemmas of professionalism, especially if we link it to Strathern's insight that current processes of externally-driven 'self-evaluation' make that 
boundary a difficult one to draw, as our data will also indicate (Strathern 2000). Indeed, it is important to recall that even the notion of the 'total' institution was introduced by Goffman as a 'social hybrid' (1961: 22) whose inmates are best ruled when caught in the 'tension between the home world and the institutional world' (ibid.: 23-24). It is the nature of that 'in-between-ness' that interests us here, rather than any simplistic preference for one over the other. Consequently, we will not follow Dawson to his conclusion, that professionalism involves in essence, a professional search for humility' (ibid.: 153), but extend the inquiry in less essentialist ways by instead asking: what is it that exercises the tensions between the inside-out and the outside-in within professional discourses? how are these tensions expressed and/or resolved by professional subjects in regard to their duties? are they necessary tensions for professional performances? and what are the implications for contemporary professional theory, if indeed the notion of the 'professional' is to be sustained? Perhaps a final question will turn out to be: how can the deconstructive or dialectical potential of each of these registers in relation to the other be realised as a contribution to a form and theory of practice?

As we saw, then, the professional was often portrayed as caught between polarities. Professionalism, therefore, could only be understood as plural or split. Its project had to be unification. As a result, traditional academic story-telling about professionalism tended to proffer a dichotomy or typology, span the gap(s) with an alleged 'continuum' of practices, locate 'typical' characters along it, and pronounce the 'endings' of deprofessionalisation, proletarianisation, de-skilling, or, more rarely, enskilling and reprofessionalisation. Finally, these might be linked to the broadest themes, such as 'modernity', 'capitalism', 'bureaucracy'. In such metanarratives, terms like 'typical', 'continuum', 'role' and 'identity' are implicitly regarded as 'extrametaphorical': they methodically pre-order the narrative, and an orderly and settled schema emerges. It can then be given a suitably static name, like 'landscape (Clandinin et al 1996) or 'schema' (Jameson 1983) and an appropriate title, because it forms a picture - 'bureaucratization of professionalism' (Murphy 1990: 75), 'juridification' (Bertillson 1990: 115), 'audit culture' (Power 1994), 'balkanisation' (Hargreaves 1994), 'coercive accountability' (Shore and Wright 2000: 77). It's good news for Humpty Dumpty: things come together again even if there is seldom the promise of a happy ending.

Our interest here is in the disorderly movements that such resolutions suppress, or perhaps it is fairer to say, disregard, because these self-same accounts also talk a largely neglected language of movement. For example:

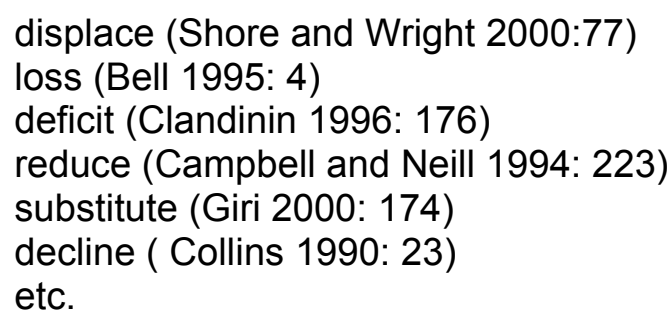

These amount to an unexplicated discursive dynamics around the notion of 'professionalism', an idea that is itself in motion within a 'culture on the make,' as Strathern puts it (2000: 1), and subject to 'conceptual inflation' (Shore and Wright 2000: 59). How then can we articulate such burgeoning movement and contrast it with the alleged stasis of a variously wrought epistemological determinism? Can such an account find empirical support in our data on teachers' and nurses' experience of their work? 
Before turning to those data, it is worth observing that social pluralities are often held to imply a prior (or prospective) nostalgic unity. For example, Day and Hadfield claim:

'...teachers' learning about teaching is through a mixture of formal training, personal experiences, reading materials, advice from other teachers, and the transference of ideas and understandings from their personal lives and biographies. This has resulted in the content of their professional theories and the "architecture of their professional selves" (...) becoming discontinuous and fragmented.' (Day and Hadfield 1996:149, our stress)

What is the unaddressed weight of that 'becoming'? It implies a prior wholeness, and illustrates a pronounced tendency of accounts of the 'professional' to seek holistic succour in a mythicised past, or a utopian resolution in some future state of imagined grace. We intend our story of professionalism to resist such holistic temptations (although we end on a note of slightly forced optimism), and to encourage a more fissiparous emplotment that will keep tensions and movement in play, rather than acknowledged and backgrounded in the same dismissive gesture. But first a necessary confession. It is currently fashionable at this point in the argument to bring on 'difference', 'fragmentation', 'hybridity' etc as the new language of a postmodernist, deconstructive envisioning. The problem is that such attempts often end up re-framing the central ideas that they address, instead of also un-framing them . Such an un-framing would resist any epochal or paradigmatic readings of 'postmodernism', that Cretan Liar of a term.

The first 'reframing/unframing' undermines the stable, unitary notion of the 'professional'. We draw here on Pels' account of the liberal self which refuses to countenance romantic and utilitarian 'moments' in European history as separate. As a consequence he identifies the notion of the 'liberal self' as mobilised by a dilemma:

'Liberal selves, therefore, can choose between two possible ways of defining an escape from political contingencies: when criticizing the objective facts of capitalist society, they romantically imagine an ethics to reform it; and when criticizing the subjective imaginary of romantic ideas, they fall back on utilitarian arguments about how the world is factually constituted...' (Pels 2000: 149)

Pels also concludes that the 'double life of the liberal self' involves a 'simultaneous posing as an untutored self and as the standard towards which it needs to be tutored' (ibid.: 155). We take the professional to be an expression of a 'liberal self', and hence to be seen as contested not just in terms of social status, but ontologically and historically split in ways fundamental to our culture and economy. We draw also on Rappaport's view of the oscillating dilemma of contemporary professionalism:

'What we require is a model which allows us to play within the dialectic and to pursue paradox, first to one side, then the other: one which allows us to welcome divergent reasoning that permits many simultaneous, different and contradictory answers, rather than a single solution to every special problem.' (Rappaport 1981: 16)

The task of the professional, then, seems an irresolvably ambiguous one, and this articulation of the role, as we hope to show, offers a provocative approach to the sorts of economies and ecologies of professionalism that we intend to develop. Implicit in such tensions are the much-discussed dilemmas posed between accountability, trust, risk, and professional excellence. 
The second 'reframing/un-framing' perspective concerns boundary rather than role. As we saw, Larson employed the metaphor of the 'battlefield' in order to envisage professionalism as expressed within a Foucauldian 'discursive field':

'These are best seen as battlefields, wherein different kinds of expert fight for preeminence and where other, "non-expert" forces also intervene. I want to argue forcefully that the degree to which these arenas of struggle are open to common citizens is both a measure of democracy and one of the stakes of democratic politics.' (Larson 1990: 35)

This is professionalism exogenously defined as struggle, contested with others, and Larson concludes that the key is the 'relation of different categories of professionals to the production of discourse' (ibid.: 35). To contested status and philosophy, then, we can add a conflictual politics of professionalism. Larson adds a point that we will later expand:

'...conflicts which become political projects, exceeding and transforming the boundaries of the discursive field, tend to be fuelled and expanded from the outside or from the margins, by both unauthorized speakers and experts who abandon the professional mode.' (ibid.: 40; our stress)

This is 'outside-in' professionalism with a vengeance. The political conflict relocates the centre of debate outside the profession itself, leaving the professionals mere spectators. Accordingly, one rescue strategy (amongst many others) in such embattled professions is of course to change sides, 'to abandon the professional mode' in favour of more successful and dominant contributors to the discourse. On both of these phenomena, more later.

The third reframing/unframing that we wish to undertake concerns the profession as 'a symbolic hybrid between the past and the present' (Larson 1990: 44; our stress). We take that to mean that professional talk is not just about procedures, rules, or customs. Nor is it simply the public discourse through which a body of workers 'profess' to their lay audiences and clients. It also involves the symbolic nature of professional talk (and we must include ourselves in writing about this), and how such talk constructs and is constructed by past and present. We would add, after Falk, that future time is also very relevant, and indeed 'catastrophic future time' (Falk 1988) features strongly in the professional discourses that concern us in this paper. Mental Health Nurses lament the possible decease of their profession - dissolving into 'the generic health worker' - and teachers express their future (or have it expressed for them) in terms of a proletarianised nightmare of 'compliant technicians.' (Helsby 2000: 107; Scott 1998; see also Apple 1992)

Finally, there is a more radical 'reframing/unframing' that must consider what it is possible and not possible to say about contemporary professionalism. This account does not set out to offer a new, stand-alone, self-sufficient and 'superior' account of professionalism, or post-professional work, as we may eventually have to call it. 'New times, new truths' misses the point completely. Instead we want to 'unframe' methodological conventions, and their conventional application to data; unsettle theoretical conventions, and their various appeals to the ecologies of the micro, meso, macro and chrono (Bronfenbrenner 1986; see also Bottery and Wright 1996: 86-87). In this way, we aim to create different possibilities for 'professionalism', and especially ones that resist the increasingly universalist, essentialist, reductionist accounts that seem to appeal to governments, media and their agents - including educational researchers content to be the 'compliant technicians' of these 
developments. We seek, therefore, to develop an 'uncertain' theory of professionalism.

'The anthropologist's kind of ethnography grasps not just the contingency and unpredictability of social life, then, but how description and self-description contribute to it. And in a world saturated by "information", including expert knowledge distilled as information, maintaining a diversity of descriptive forms begins to seem important for its own sake.' (Strathern 2000: 287)

We turn now to a more empirical scrutiny of teacher and nurse data, drawing mainly on teacher evidence in order to elaborate a theory of contemporary professionalism. Nevertheless, it is claimed that concepts and theories so derived can usefully be deployed in understanding the role of the mental health nurse. Following this empirical section, we will finally seek some more general conclusions about professionalism today.

\section{There is no such thing as a teacher or a nurse.}

The qualitative critique of quantitative research introduced both the individual 'subject' and, later, the 'person' of the researcher as appropriate research objects (Stronach 1999). These 'individuals' were usually given a substantial core identity (stable, definitive, essential) that enabled them to be categorised, typologised, and so on. Our readings of both teacher and nurse 'identities' suggested a more fragmented possibility. Within their overall self-presentations professionals offered mini-narratives of identification; unstable, shifting, sometimes contradictory or expressed as conflicts. These shards of self-accounting belie the professional as 'type':

- teacher as recollected pupil

- teacher as pressured individual

- the subject specialist

- the person/teacher I am

- the socialised apprentice

- the coerced innovator

- the convinced professional

- professional critic

- sceptical pragmatist

- etc.

These 'shards' were variously mobilised by teachers to account for their overall response to contemporary teaching initiatives and conditions. Thus for example the same teacher might assert the need for autonomy ('you've got to have your professional judgement'; professional critic), criticise the nature of an innovation ('does tire you out'; pressured individual) while simultaneously praising the initiative ('thoroughly enjoyed teaching it'; convinced professional). She might also acknowledge its impact on her own initial lack of subject expertise ('... it has helped me [...] as a normal person who had a negative experience'; recollected pupil), and confirm an increased sense of worth ('I feel a lot more prepared'). Rather than read such data as reducible to a larger and more stable label, such as 'supportive conformist', 'surviving conformist', or 'non-compliant' as Woods et al might suggest (Woods et al 1997), we prefer to read the professional as mobilising a complex of occasional identifications in response to shifting contexts. These mobilisations amount to a kind of internal emplotment of professional selves. Their resolution is a denouement rather than a definition. 
Mental Health Nurse identities could equally be read as non-unitary, fragmented, shifting, and often contradictory and unrealized. For example:

- the 'blurred role' of the nurse

- the MH nurse as giver of the depot

- the bed manager and form-filler

- the go-between

- the evidence-based practitioner

- a 'jack of all trades'

- 'get 'em in, patch 'em up, ship 'em out'

- etc.

'I think it's actually right that sometimes we actually want to look, to see, to improve things, to evidence-base, but the reality at the moment is that resources are so tight you actually can't do all of those things - you haven't got time, the resources, the backing...'(MH nurse)

'I can spend most of the shift filling in forms of one form or another. It's strange that as the ward gets busier and more dangerous, the more forms I have to fill in, in order to record how busy and dangerous it is.' (MH nurse)

In general, teachers seemed to portray their roles as over-crowded and conflicted: in Gluckman's phrase 'cross-cutting identities' that tend to set up what he called 'oscillations' between alternating political states (1963: 37). The nurses we spoke to experienced their roles as rather more 'hollowed out' in that they felt uncertain (amongst many conflicts) about what in fact was their role. Theirs was rather a crisis of non-identity, frequently expressed as an uncertainty and uneasiness about identity, role boundaries and client relationships. In brief, our teachers experienced their professionalism as something they had lost; our nurses as something they had failed to find.

\section{So 'a professional' is plural and 'the professional' (The Nurse, The Teacher) is a false singularity.}

Our readings of the nurse and teacher data offered fragments of narrative that it took considerable symbolic violence to stabilise as essential identities, stages or types. They did not characterise an entity so much as they depicted dynamic and ambivalent aspects of situated performance. Nor did they readily sort into core or periphery aspects of identity. Indeed such stories were often told dialectically against each other, the narrator caught between stories, split between grounding narratives that offered different versions of a professional self along with tangential manifestations of a personal self. The following example from our data shows a teacher claiming an essential identity (teamworker) in relation to fellow professionals with this authenticating plea:

'...we are very much a team.'

But that essentializing claim is far from unambiguous. Elsewhere, the statement is repeated, but with a difference: 'I very much work with a team, as a team'(our stress). 'With' and 'as' juggle with an authority relation in regard to the team, the 'as' perhaps belatedly inserting the individual within the team rather than locating him in a more authoritative outside relation. The latter possibility is then projected as a hypothetical relation, placed elsewhere than the present in time: '.. at the end of the day [note the bottom line] .. if ever I did want to - not that I ever would - say to them "look I am 
sorry but as deputy I need to come in"..' In this way, authority is both denied (practically), asserted (hypothetically), and privileged (definitively) with that reference to an 'end of the day' status. The 'we' splits, a 'them' emerges. Elsewhere, the teacher's 'teamwork' identity is further clarified/muddied with an analogy distanced in place rather than in the time-frame of the 'end of the day': '.. [class teachers] haven't got the same kind of authority, if that is the word you want, we are not hierarchical here, but it could work out in some schools, the deputy goes in and says "look, you are doing this, I am the deputy"'. Despite these caveats, his conclusion returns to the essentializing claim: 'It doesn't work like that here, we are very much a team and everything that we achieve is as a team'. Our point is a simple one. 'Authenticity' and 'voice' are neither self-apparent nor easy to reduce convincingly to types and styles: teachers make complex and shifting warrants for their practice. An apparently simple and deeply held identity claim ('we are very much a team') is a claim to collaborative professionalism hedged round with ambivalence and contradiction. Its notions of 'knowledge' and 'self-knowledge' have to be understood as woven in and around power claims that are both withheld and asserted. These conditions should not surprise us, given the inherently ambiguous locations in which professionals find themselves, as earlier noted. (Pels 2000; Cant and Sharma 1998; Larson 1990; Rappaport 1981)

Most often, professionals acknowledged a plurality of roles (it might be better to rename those 'typical engagements'), uneasy allocations of priority, and uncertain attributions of 'identity':

'It's a bit like juggling - you have to please your manager and the Trust, you have to please the clients, and at the same time you have to keep yourself updated professionally.' (Community Practice nurse)

'...I see them [nurses] get frustrated with it [the job], like "we're not just CPA [ Care Programme Approach] key workers, we're nurses", but when we talk about that, they can't put their finger on it either, it feels lost.' (Occupational Therapist)

\section{Professionals are not just plural; they are inherently split, in ways which 'define' the role.}

Nor were such plural accounts stable. In conditions felt to involve growing professional uncertainty, the nature of 'good practice' or the adequacy of long held ideals (such as hands-on client care, child-centredness, holistic practice) became symbolically vulnerable. The result seemed to be a constant jockeying of stories, selves and practices as teachers and nurses tried to come to terms with a welter of recent innovations, the pressures of their respective audit cultures, threats to their preferred professional styles, or otherwise accommodated or resisted political attacks and external impositions. The notion of 'juggling' recurred both in the literature and the data. Barker refers, for example, to mental health nurses 'toggling' between different selves (Barker 1998: 280).

Much of the 'juggling' in our data expressed a reworking of individual professional commitments, usually invoking some singular alleged state like 'autonomy', 'clarity', 'responsibility', 'fulfilment', 'trust' or even 'romance' that had somehow been compromised in the present or denied for the future:

'I am trying to develop their independent learning skills, which should have gone on earlier in the school. I am having to do a lot of that now but because of the pressures from outside as well, because of the mismatch between how we are supposed to 
teach and how naturally (our stress) to test the children's knowledge - because of that mismatch I am having to go more formal...' (teacher)

'I became a nurse because I have a greater interest in people's health care needs rather than their social needs. People became social workers because they are more interested.. or they don't want anything to do with the health issues, thank you.'(nurse; our stress)

'It seems that when you qualify that is it, that is what you are good at doing. You do all the paperwork and the support workers do the care which you were trained to do. You just facilitate it.'(newly qualified nurse)

In the first instance, the teacher juggles with her own professional goals (independent learning skills) and external pressures from tests. As a result she feels coerced into a pedagogic approach she would not otherwise have adopted, and which stands in some contradiction to her own goals, if we believe that increased formal teaching will not promote independent learning. That is the dilemma of her 'resolution'. In the second case professional commitment had been threatened by a 'blurring' of roles, and it is important to note the implications of 'became': the verb implies 'professional' rather than 'occupational' allegiances. Here, as in the third quotation, it is the dilemma of a displaced professionalism. But all three quotations suggested frustrated identity claims, not just changed job descriptions. Such tensions were commonplace in both sets of data.

Nor was 'juggling' simply a matter of individual professional compromise: the pace and pattern of work was seen to disrupt the experience of doing a 'professional' job. This change of regime also undermined vocational commitment by making it harder to realise what were seen to be the real rewards of professional work, as in the 'blossoming' of children, the 'creativity' of good teaching, or in this account of contemporary ward work where, again, the reference was to a nostalgic holism:

'There used to be a time when, yes, it was nice to come to work because you felt as if you got a reward from being at work, there was a final... people got well. Now it's like the revolving door [...] pressure, pressure, pressure [...] there's not the "thank you" letters on the wall.' (ward nurse)

The fragmentation of work was a recurring theme ('nurses do little chunks now'): our nurses seemed to feel a loss of the whole professional story leading from diagnosis and treatment to care and cure, 'broken stories' as we came to call them. But again these were not unambivalent jugglings because the same nurse later went on to conclude '...yyou see the patients getting better, and well, and out. OK, there are a certain number who are in the revolving door, and the frustration, but the majority of them outweighs that.'

We will later say more about these dynamic processes of change, and meanwhile merely note that such individual changes can be experienced in a number of different and frequently contradictory ways, both positive and negative.

But there were plural as well as singular allegiances expressed in both nurse and teacher accounts. These also set up tensions of a more interpersonal sort. In the case of the teachers, a collective allegiance was expressed (involving a group of teachers, a stage of learning, occasionally a school). $\mathrm{MH}$ nurses made similar appeals to a collective expression, for example, in claiming to share 'a very black sense of humour', of maintaining a certain kind of work atmosphere that other 
occupational groups like social workers found different and difficult: 'We're very jokey about things, fairly light-hearted. I think that's quite a good way of getting through the day'. The social workers, by contrast, were not amused.

Both of these occupational groups, then, appealed to a like-minded constituency of professionals - usually a 'local' appeal in Gouldner's terms.

But there was also - and increasingly - a corporate dimension to allegiances, relating to the management ideologies and prescriptions of the school or clinical base. These generally articulated aspects of the 'audit culture' in both settings, and expressed the greater degree to which the work of both professions was 'managed' by the external specification of competencies, skills, routines, timings, and so on. They expressed, in Peloille and Jamous' terms (1970) the attempt to spell out the 'technical' aspects of the role and rein in the more 'indeterminate' aspects. For example, one teacher considered the notion of 'whole class teaching' and offered this corporate 'take':

'...they [certain pupils] are the ones who can make this difference in the percentage. You could get $50 \%$ of them to reach level 4 and 70 odd \% what they are aiming for, they are the ones who make the difference. Some will sail through but they are the group - the borderline - they are the ones who make the difference.'

A senior nurse offered a similar sounding discourse:

'Since we became a trust l've had to make a 3\% CRES [cash releasing efficiency saving) every year. I cannot say to a CPN [community practice nurse] that as from next week I only want you to work 30 instead of 37 and a half.' (Community Team Manager)

Such tensions operated for nurses within the economy of performance now encapsulated in the NSF [National Standards Framework]. As Health Minister Dobson put it in 1999: the NSF attempts to 'spell out national standards for mental health, what they aim to achieve, how they should be developed and delivered and how to measure performance in every part of the country'.

Another teacher noted the increasingly 'corporate' nature of her school, commenting that 'there's a lot more year band planning going on, a lot more people working together [...but] still a bit of tension about that'.

It was clear that this corporate reference invariably 'passed through' a discussion of external indicators of teacher and school performance. In Latour's terms these indicators acted as an 'obligatory passage point' for professional discourses on 'effectiveness'. (Latour 1990: 151 - 153)

Thus our teachers and nurses were often in tension with themselves, and also with different work relations of one kind or another. A further tension existed with 'them'the 'powers that be' - whether management, professional boards, local education or regional health authorities, Ofsted, or the National Institute of Clinical Effectiveness. Unlike 'collective' views which were more likely to be expressed as 'us', corporate perspectives had a more hierarchic feel: 'it's the head's responsibility to get the Numeracy throughout the school'. Professional selfhood was often a matter of addressing and 'resolving' these tensions and splits, whether in acts of accommodation, resistance, compliance, subversion -or, more commonly, a kind of bureaucratic cautiousness: 
'...high profile failures of the care in the community policy has meant nurses have become more defensive in their practice. Mental health nursing used to be about responding to those in trouble. Now it's about responding to those who cause trouble.' (Ward Manager)

Accordingly, we conclude that professionals walk the tightrope of an uncertain being. It is important, then, for theories of professionalism to hold on to these notes of ambivalence and contradiction, rather than try to reduce or resolve them in the ways earlier criticised in this paper. And if professional roles are experienced quite deeply and frequently as a series of dilemmas, it is to a theory of the nature of those dilemmas that we must turn.

\section{4. 'Professionals' juggle between 'economies of performance' and 'ecologies of practice'.}

We began to develop a number of patterns in the sorts of appeal or 'warrant' that both teachers and nurses made in relation to their professional practice. One set of warrants involved a 'language of indicators' (Strathern 2000: 314), and for reasons of brevity, we concentrate here on our teacher data. In the case of teachers these involved league tables, SATs levels, targets, OFSTED ratings and the public ranking of pupils, teachers and schools against such performance criteria. As we've seen, the NSF places a similar matrix of targets, measures and normative comparisons on the nursing profession. The depth of penetration of such audit-led registers had already produced in both professions a new and arcane professional discourse. For example, the teacher who was earlier quoted as saying 'gosh this target' went on to elaborate the conundrums of her $65 \%$ level 4 target for her class:

'One is hearing impaired, one has got a statement and the other two, special needs. So, you are talking about all them, and we have also got another four children who are generally low level attainers as well, so you are talking about 8 out of the 27 . It is quite a large percentage to start working from that baseline.'

These concerns for levels of attainment and public comparisons, then, bred a new language of educational discourse, and constituted just the sort of 'obligatory passage point' that Latour noted. Debate centred, in our teachers' accounts, on SATs, which tended to be accorded a kind of 'end of the day' priority: '..only the SATs will tell, won't they? That's the panicky bit'. This sense of ultimate judgement could be reassuring but was more often felt to be threatening - over-riding any possible 'professional' judgement:

'That was why I was so disappointed when I had Year 6 last year because I felt I'd given them so much and when you saw the answers they'd put on the paper you could cry. I really, really, felt dreadful. That wasn't the way l'd done it.'

Children were also redefined within this new register of accountability: 'level 5 children'; 'someone at the bottom lower key stage 2'; 'level 2s cum level 3s', and even encouraged to learn this new language: 'I use the terms ['targets'; 'level 4'] with them as I do with the Literacy, because I am very much into the Literacy Hour..' This kind of discursive inflation flowed from the test results through school reputations, the identification of staff development 'needs', and the ongoing assessment of pupils, as one Deputy Head explained:

' $[\mathrm{We}]$ agreed as senior management that target-setting would be an excellent vehicle for actually monitoring and tracking pupil progress whilst also addressing the 
professional development needs and use the data that we had collected there to say, "shall we do this, shall we do that?"

In this way, schools sought to 'define their mission' and promote their position:

'...the expectation now from staff that they are going to try to move up within 2 notches each time --each year group - and so actually span two levels, over the national expectation.'

'...it sounds awful, but as a school you want your SAT results to look good, so you have to teach towards the SAT papers.'

These coalescing registers of pupil assessment, staff training, and performance measures, constitute what we came to call an 'economy of performance' expressed largely in terms of quantitative performance measures. They required universal curricula in order that standardised comparisons could be made locally and nationally, and so were felt to imply 'delivering' a set curriculum. This degree of professional 'performance' regulation is much decried in the critical literature but again we should be careful to record that our teachers' responses, particularly in relation to aspects of curriculum and pedagogical imposition, were often positive:

'I was very pleased about it, yes, because it is there in black and white and people can't have their opinions about it.'

'I actually quite like the Numeracy because you can't not teach something (...) It tells you all the time what you have got to achieve. It is there and you must follow it.'

Indeed the NNS could be seen as a welcome increase in control compared to the 'vagueness' of the National Curriculum: '[w]e hoped it was going to be a bit more prescriptive as this [Literacy and Numeracy strategy] is. To me it [the National Curriculum] was very airy fairy.'

Such an 'economy of performance' seemed to dominate professional performances in our sample from both professions, although in nursing the effects on professional discourse seemed less pronounced. Nevertheless it was clear that such an 'economy' was always written against other beliefs and practices. Professionals' talk was shot through with different warranting appeals. As well as those auditable commodities of the 'audit culture' (OFSTED ratings, SATs results, league tables etc) professionals in both groups made frequent appeals to different sorts of registers which we came to label 'ecologies of practice'. These comprised the accumulation of individual and collective experiences of teaching or nursing through which people laid claim to being 'professional' - personal experience in the classroom/clinic/ward, commonly held staff beliefs and institutional policies based upon these, commitments to 'child-centred' or 'care-centred' ideologies, convictions about what constituted 'good practice', and so on. These generated a tension for professionals, and it seemed to us that it was in living this tension, with its contradictions, dilemmas, compromises etc that they experienced themselves as professionals. The job of understanding professional 'work' and 'belief', accordingly, involved reading these tensions, and locating 'professional' experiences betwixt and between these affiliations. (It follows that we are sceptical about whether there can be any such thing as an 'audit culture' as such, except as a highly metaphorical deployment of the notion of 'culture'. No-one inhabits the audit culture, even although it invests everything.) 
The economy of performance was not restricted to external sets of measures. It also involved, in a way that overlapped with various ecologies of practice the sorts of curriculum and pedagogical specifications that reconstructed teaching, or to a lesser erxtent nursing, as a fully auditable commodity:

'...it's [numeracy strategy] certainly increasing your accountability, but (our stress) it's making children's progress measurable, and it's putting that in the context of "what do I need to do next?" "

Note once again how ambivalence in relation to teacher performance reappears in that deployment of 'but': our reading would suggest accountability as projected negatively in relation to teacher performance ('increasing your accountability') but positively in terms of pupil performance ('making..progress measurable'). The audit culture as good for you but bad for me? We would argue that the reasons for such ambivalence are centrally important to understanding contemporary 'professionalism' for both of these occupational groups.

An important aspect of an 'ecology of practice' lies in the sorts of warranting appeal that professionals made to what they took to be their personal/professional orientation:

'my preferred style of teaching.'

'my preferred style of learning.' (for the children)

'my approach to teaching.'

'what I call real nursing.'

Such an orientation might cause friction ('I am not $100 \%$ with, I think the bright ones tend to get quite bored'), or offer reassurance:

'It wasn't until this came out and I thought crumbs that's what I do, that's what I like to do, and now I can openly do it.'

Or any number of positions in between: 'That's how I am sorting it out at the minute, yes - just with my own ideas with years of experience'; 'I am confident and secure enough to think I am doing my job well enough and I can justify what I am doing' In our sample of primary teachers, talking about the teaching of numeracy in their classrooms, this professional orientation was often a negative one in relation to subject expertise, invoking the person of the 'the recollected pupil':

'I don't even have Maths O level.'

'my only concern is for my own subject knowledge.'

'sometimes I thought, how can I teach this when I don't understand it myself.'

That negativity sometimes also extended to pedagogic content knowledge, where teachers might find that the prescribed pedagogy was more sophisticated than their own, or even be educated by the core subject knowledge contained in the curriculum: 'I never knew this before, but when you added odd numbers together all the answers were even numbers. Now who could believe the delight I had when the kids and I discovered that together? Well I was delighted. Why had nobody ever told me? So there you go.'

These pedagogical limitations were particularly clear in relation to what teachers took initially to be an 'itty-bitty' curriculum that 'jumps around too much'. The spiral approach was criticised at first, but later they were sometimes surprised at how well it seemed to work: 
'I think that it is amazing that, especially when you have not thought about it like that, they [pupils] remember it and put it together.' It was 'coming together like a jigsaw puzzle'.

Evidence of the impoverished 'ecology' of the primary-teacher-as-maths-teacher extended from core knowledge, through pedagogy, to a deep vocational uncertainty about the status of mathematics in the curriculum:

'Probably where I feel least confidence is that deep down I know that I don't know really where the child is heading to as a person who might want to do calculus [calculus is not on the curriculum and we take it to be a metaphorical allusion to the arcane nature of mathematics], because I don't have any idea what this means. Deep down, although with all the other topics, if one of my children wanted to be a geographer, I know where I leading them to (...) and that is where I feel lacking in maths because I don't know.'

Clearly, the sub-professional ecology of some maths teaching meant that the 'economy of performance' was at once seen as threatening, because it made performances visible in a way that they had not been before, and also welcome, because such degrees of specification of content and pedagogy came to be an advance on current practices. Better a compliant technician than an incompetent professional:

'...you haven't really got the option [about what to teach or how to teach it], which in a way, if you're not really confident in maths, like myself, I'm not particularly confident, I find that quite good.'

The collision of 'economy' and 'ecology', therefore should not in itself be seen as a morally coded encounter between 'economy' (bad; audit culture; deprofessionalizing; impositional etc) and 'ecology' (good; professional; solidary; voluntarist etc).

Ecologies did not relate solely to the past, present and future of individual professionals. They were also collectively experienced, and in the primary school there was clear evidence that the school dimension had been important in relation to maths teaching policies. Again, such a collective ecology could be experienced as negative or positive:

'And yet you come into school, and you pick up their policy, and such a body says "well, we do it this way", and you do it that way and then you could kick yourself.'

A further ecological dimension involved particularising the children and educational setting in relation to perceived educational and social potentials, and being able to differentiate between various individual and school class characteristics: ' one group of children is entirely different to the next group'; 'you have got to watch your children'; 'knowing when children are ready to move on'. But the most influential aspect of ecologies of practice seemed to be the crucible of classroom experience. It was there that innovations seem to have been tested, adapted, resisted, embraced, or ignored. It was there that things had to 'work'. And it was there that a sense of the vocational commitment and reward of the teacher was most vividly expressed:

'I like giving children different ways of working out problems, I get a buzz out of it.'

'She'll come up to me and say, "I really like maths now," and you think, "Oh thank you, l've done that".' 
This kind of proof-of-the-pudding ecology seemed inherently adaptive in nature, and involved a re-working of the 'economy' in terms of their own 'ecological' allegiances, and vice versa. It was the classroom (or the ward) that 'warranted' change in the end, and what seemed initially to be a 'rigid' imposition was sometimes made 'fluid', and sometimes enjoyed for its 'rigidity': 'Its structure (...) when you first get the structure you think oh my god l'm never going to stick to that but by the end of the year you don't even look at your clock, you know you're doing it, you know your time band, and I just like the rigidity of it'

'I would like more input for me at a personal level (...) in terms of being more creative with Maths because now I am happy that I am delivering the curriculum.'

This last theme reappeared elsewhere as a fear that repetition was the enemy of good teaching, and that an element of creativity was necessary in order to avoid returning to being 'bored and boring' maths teachers.

We can see that these ecological appeals were accommodations to the externally framing 'economy of performance'. They called forth different characters, like the 'recollected pupil', 'the coerced innovator', the 'convinced professional'. These were cast in a shifting and conflicting emplotment of the 'economy' within a series of changing 'ecological practices'. It became apparent that what was interesting was not any attempt to 'name' identities, nor even to attempt to define boundaries between economy and ecology in terms of 'characterised' outcomes (like 'deprofessionalization', 'audit culture' and so on). More interesting was the discursive dynamics between these different sorts of pressure. It was a theory of 'tension' that was needed rather than some reductive formula that would identify what was 'really' going on. Professionalism was 'caught' only in that sense, and we became increasingly unhappy with static notions such as 'audit culture', useful indicator though it is of an important development in 'governmentality', as Foucault would have had it.

\section{The professional riddle: what's inside outside-in and outside inside-out?}

A. Post-professionalism? Dawson, it will be recalled, posited two forms of professionalism, 'inside-out' professionalism resting on Aristotelian qualities, and 'outside-in' professionalism which relied on the prior specification of rules and procedures. Such a characterisation is helpful, but too unitary given our fragmented account of 'teachers' and 'nurses'. It is also too morally obvious in relation to the data that we have examined. In some circumstances the outside-in aspects of the 'economy of performance' may provoke more effective treatment or instruction (eg: the 'sub-professional primary maths teacher'; 'the evidence-based nurse'). In other circumstances, where for example the professional is highly experienced and skilled, they may limit effectiveness as well as moral agency (eg: Dawson's argument against ethical prescription as an erosion of professional responsibility). The optimal mix is a matter of local analysis, not universal specification. That analysis must address the various characterisations of the 'professional' that are in play in any performance, and relate these to what we would claim to be an inevitable series of splits in the nature of professional performances. The notion of the professional as split between a number of allegiances was clear in the literature - private and public performances and their indicators, romantic and instrumental allegiances, untutored performance and hoped for future standards. The 'uncertain being' of the contemporary professional was also clear in our reading of the data. What, then, is optimal? 
If professional lives are to be understood in their complexity, plurality and inconsistency, then one requirement may be that of a 'narrative adequacy', the possibility of a 'good story' (Ryan 1996: 633). Our data on the 'broken stories' that so frustrated some of our nurses would support that criterion. A second requirement would be that professional performance should be interpreted within a broad 'moral landscape' and not be reduced to 'a single standard of commensurability' (Helgason and Palsson 1997: 453). They point out that it is a cross-cultural commonplace for such reductions to be resisted in both folk and scholarly discourse as a battle against commodification and inequality, if not an anti-colonizing resistance. Again, our professionals were keen to take a holistic view of their performance. A third requirement would be for professional diversity rather than the current drive to identify 'national competencies' and ensure conformity. As our ENB research concluded, the 'fantasy of a once-and-for-all remedy' for the dilemmas of professionalism is managerially tidy but may not make professional good sense:

'The more diverse, plural and unpredictable professional work becomes, the greater will be the managerial pressure towards homogeneity, singularity and coercive specification.' (Stark, Stronach, Warne 2000)

'The more precisely you specify a professional performance, the easier it is to measure and the harder it is to motivate.' (Stark, Stronach, Warne 2000)

A final requirement, then, is for the development of professional forms of trust. Such trust implies risks; and risks are part of the 'indetermination' of the role (Jamous and Peloille 1970) as well as an ethical necessity, as we have earlier argued. This has been long understood and only recently forgotten. Now the danger seems clear: '[t]he language of indicators takes over the language of service.' (Strathern 2000: 34).

B. Agreeing to differ we promised to read our data 'against the grain', and tried to show earlier that current theories of professionalism were guilty of highly reductive characterisation. Even where the 'composite' professional was envisaged (Troman 1996: 485), and where the 'contextually variable and contested' nature of professionalism was asserted (ibid.: 476), there was a tendency to return to unitary endings such as the 'new entrepreneur', or singular descriptors such as 'strategic compliance' (Shain and Gleeson 1999: 456). Our intention in this article has been to find a way of characterizing professionalism, methodologically, that avoided the 'grounded theory' prejudice for similarity and against difference, and read for rather than against notions of identity as 'inner diversity' (Hird 1999: 523). This is not to say that we privilege difference over similarity, only that we wish to retain its possibility against the homogenizing tendencies of conventional qualitative data analysis. Our criticism is that conventional clustering techniques of meaning-making more or less inevitably result in formulae like the 'new professional' (Hargreaves 1994), the 'new entrepreneur', the 'old collectivist' (Mac an Ghaill), the 'technicist professional' (Furlong 1992, all cited in Troman 1996). Instead, we tried to preserve difference, movement and particularity, while acknowledging that these pointers to 'locality' are by no means unconnected to the global and the universal, and so cannot reasonably be regarded as 'grounded' in any convincing sense - this was not a phenomenological holier-than-thou project. One strategy we employed was to look for notions that caught the in-between-ness of professional work.

We would also claim that such an approach to generating meaning from 'data' allows a more fruitful interplay between the sorts of contemporary poststructuralist debates on the nature of 'split identity', 'liberal selves' and the 'audit culture'. Such an 
approach stands in some contrast with much of the inductive theorizing typical of qualitative research in this area:

'From that data we can begin to move towards theory, to find whether there are any common patterns in different biographies, so to work toward "the developmental generalized formulation of careers" that Glaser (1964) called for.' (Measor 1985: 61)

C. Economy of performance/ecology of practice. The concepts of 'economy of performance' and 'ecologies of practice' allowed us to get a purchase on outside-in and inside-out issues, as well as local and global ones. Clearly the 'economy of performance' for both professional groups tended to give expression to 'universal' rather than 'local' models of good practice (Gudeman 1986: 32). In Gudeman's terms the 'economy of performance' was based on the 'primal metaphors' (ibid.: 40) of 'measurement', 'effectiveness' and 'improvement'. These were integrated in a model which was also prefaced on Economic Man and a broadly neo-classical economics, that is 'derivational, universal and strictly rationalist' in the ways that Gudeman's economic anthropology would anticipate (ibid.: 32). 'Local' metaphors, on the other hand, were more inclined to involve primal metaphors like 'child-centredness' and 'holistic care', although as we have argued it was the various imbrications of these registers that was of most interest.

We concluded that these different registers helped us understand the mechanisms through which professional features - like autonomy - were constructed or undermined, and how managerial/professional boundaries were policed. They were also a useful scissors for understanding the dynamics of change in institutional settings. In particular they allowed us to address the degree to which the 'audit culture' had penetrated professional life. Most important, the ways in which professionals addressed these competing registers allowed us to construct an account of the discursive dynamics that attend current professional performances. We criticised various emplotments of these on the grounds that they were too reductive and polarised - politically and methodologically. We also criticised the 'audit culture' formula on the grounds that it offered a one-dimensionality that we found unconvincing. Our data would rather suggest that an economy of performance - however dirigiste - called forth ecological responses, even if these were limited in the first instance to tokenism, or the with-holding of enthusiasm. Nor would we accept an inevitably 'deprofessionalizing' view of an economy of performance, since we have instances in our data that suggest that coerced change can be welcomed:

'...it's [numeracy strategy] actually given me a framework to actually teach the strategies whereas before you were, say, "right we're going to do this, we're going to add" and perhaps you'd only teach them one way but now l'm teaching them loads and loads of different ways'(primary teacher)

Note that in this case it is the 'ecology' that was restricted, and the 'economy' that opened up a diverse and 'more' professional response. Again, we would stress a situated reading of the discursive dynamics that engaged these different registers, and a plural/split view of the professional self as a situated aggregation of 'mininarratives' deployed in the construction of a professional story (whether realised or frustrated). Reflexively, professionalism is the realisation of such stories.

Nevertheless our data would indicate that the sort of situation outlined by Lambek was more common. In Lambek's account, the role of morality was irreducible to rulefollowing, and generated the need both for moral reasoning and proper uncertainty: 
'Since moral knowledge is practical, it is indefinite, and therefore, since it cannot be finitely grasped, there is no science of it' (Lambek 2000: 316).

Such inherently adaptive responses did not 'distort' so much as they registered a necessary aspect of any professional performance. This was illustrated from the data where the same professional first indicated the 'black and white' nature of a reform in educational practice, as we earlier noted:

'...because it is obviously very prescribed by what you are doing, so you can't not teach something because it is there, totally, what you have to do.'

Six months later the teacher was asked if the reform was a 'straitjacket, now do this, now do that, now do the other in this way?' Her answer was:

'I think I would be a poor teacher, I don't think I would teach if it was like that.'

Interestingly, the response 'I don't think I would teach' is a professional response [ie it addresses a putative vocational commitment], indicating what we would read as a recurring and often deeply held view of the nature and motivation of teaching. The 'economy' had to be 'ecologised' for professional performances to be motivated and to take place. A 'deliberative' dimension was inserted (Eraut et al 1995: 13). An element of 'diversity' is taken to be necessary, in a way that is in accord with Matusov's account of the role of 'diversity' in an innovative school 'ecology' in the US (Matusov 1999: 166). This relates to the essentially 'incomplete' nature of professional performance (Matusov 1999: 181) that is echoed by Willmott (2000). As in our data, professionals sought to respond creatively in order to avoid becoming 'bored and boring'.

D. Desirable impurities Nor indeed would we wish to posit as a desirable goal any form of pure 'ecology' of professional response, since that would licence the oligarchic tendencies of any occupational group first and foremost to look after its members' own interests. 'Inside-out' as a resolution returns us to the oligopoly of the 'secret garden' of the curriculum, whether relating to nursing or to school education. Such a return invokes the somewhat mythicised era of autonomy in English education (McCulloch 1990). We should not allow, then, a reference to 'ecology' (itself a warmly approving metaphor) to invoke an unexplicated moral superiority.

Such an invocation of the need for an 'outside-in' dimension, however, should not be taken as approval for Trojan Horse systems of 'self-regulation' which offer managerially rather than professionally determined a priori categories and measures of performance. In these systems Dawson's notions of inside-out and outside-in professionalism become seriously compromised. The outside comes in (as surveillance, external criteria etc) and the inside goes out (as 'transparency', accountability etc). Considerations of accountability 'gloss' the surfaces of relations between outside and inside. Thinking analogically with paradigms in architecture, such a professionalism is as 'postmodern' as the Lloyds' building in London or the 'exoskeletal' Pompidou Centre in Paris.

Approaches like these are both invalid and progressively invalidating, as Strathern (1997) has argued. Linn has also pointed to the inexorable tendency of high stakes external accountability measures to become corrupted, especially when linked to political pressures: politicians in the US are apparently fond of timing testing so that it delivers 'the impression of improvement right on schedule for the next election' (Linn 2000: 4). Linn argues that it is a feature of new tests that they demonstrate early 
gains as students and teachers become accustomed to them, and teach to them. Then comes a predictable tailing off of 'improvement'. On such a scenario, Blunkett's current target, on which he has allegedly staked his future $(75 \%$ achieving level 4 for numeracy by $2002 ; 80 \%$ for literacy) seems statistically realisable in the short term, but educationally meaningless.

'Pure' models of the 'economy of performance' vary radically in political terms. Missionary optimists support the neoclassical model. This human capital model assumes that the 'economy of performance' can somehow simultaneously draw on and reflect both the realities and the rhetorics of economic life and substantiate its own matching practices in increasingly 'effective ways' - a kind of improvement by mimesis of a mimesis. For example, Becker, in his triumphalist, post-Nobel prize reminiscence recalled that his human capital theory had not always ruled:

'To approach schooling as an investment rather than a cultural experience was considered unfeeling and extremely narrow.' (cited by Fine 1998: 66)

Such a model, according to Fine, involves first 'endogenising social relations on the basis of individual optimising behaviour', and then 'treating non-economic relations as though they are akin to market trading' (Fine 1998: 53). Positing motivation as 'utility maximization', it can then readily be translated into a benificent audit culture designed to stimulate motivation ('improvement'), add to utility ('added value'), and make education 'resemble' neoclassical economic theory ('relevance').

On the other hand, missionary pessimists take a bleakly Foucauldian view of 'economies of performance', seeing in them the triumph of 'governmentality' and the emergence, as we have seen, of a punitive, suspicious regime of surveillance or selfsurveillance. Professionals, in such accounts, are reduced to the petrified selves of audit. The enormous cost of these regimes, such as Ofsted, QCA, Clinical Governance etc is affordable: over-inspection legitimates under-investment, and indeed ideologically cloaks it, shifting media attention from leaky wards and classrooms to league tables and the 'spectacle' of defective practitioners (Dr Shipman, Nurse Allitt, Headteacher Evans). In this scenario the 'responsibility' of professionals expands enormously, along with a paradoxical reduction of their autonomy through audit control. Responsibility is devolved, but the instruments of blame are centralised and foregrounded.

So dream confronts nightmare in the macropolitics of professional lives? We would argue, however, that both accounts are overdrawn. The professional micropolitics are much more complex and inflected, even though the more negative of these universal 'scapes' were dominant for our subjects.

E. Remote control Larson, as we earlier noted, claimed that professional discourse could be 'fuelled and expanded from the outside'. Moves towards an 'economy of performance' and 'self-regulation' seem both to achieve and disguise this. In general, it is clear that professional discourses on education are controlled by government and media in relation to teaching, and are coming under increasing government control in nursing. The 'colonising' nature of neoclassical discourses has been noted (Fine 1998: 71). The expansion of the 'audit culture' is clear. At the moment, however, the contrast is striking in relation to nursing and educational research relating to schools. Nursing remains a professionally bounded discourse, although of course subject to numerous pressures, especially in relation to actual resources. Education, on the other hand, is governed almost entirely in an 'outside-in' kind of way. Consequently, the issue of what the latter professionals should do is a mish- 
mash of prejudice, stereotype, performativity, nostalgia, and what Kundera (1991) called - in relation to a decaying Stalinism - 'imagology', where invocations of teachers-at-the-front-of-the-class, nurses-at-the-bedside, and bobbies-on-the beat pass for professional/political debate. This kind of Punch-and-Judy professionalism renders the educational discourses that surround teaching and nursing 'disordered' in ways that professional work can never remedy: power lies elsewhere. Meanwhile, the disordered discourse of professional advice and admonition offers a simulacrum of order - technical reason, measured outcomes, social and economic gains. That simulacrum is shot through with personification, metonymy, elements of myth and ritual in such a way that the act of 'rational' colonisation is at the same time an exotically irrational re-presentation.

It follows, of course, that how an 'economy of performance' is negotiated in relation to the ecologies of professional practice is vital to the well-being of the profession, and indeed to its future existence as a 'profession'.

F. The ends of professionalism Goodson and Hargreaves fashionably promote the notion of a 'postmodern professionalism' (1996: 21). They take it to be a good thing. Here we argue that the capture of professional discourses, and their re-articulation as 'performances' denote the passage of such discourse to the sort of postmodern and 'performative' condition that Lyotard indicated. We take that to be a bad thing. The current rigid and coercive 'economy of performance' (as constituted by current audit and accountability practices) inaugurates, then, a postmodern professional discourse. The relocation of notions such as 'good', 'bad', 'success', 'failure' and 'improvement' - as many have pointed out - as normative references within 'effectiveness' discourses also threatens the end of educational or nursing philosophy and sociology:

" "Good", "better", and "worse" had lost their philosophical anchors and were now being dragged into normative discourses where they reflected league table positions, regionally, nationally or internationally.' (Stronach 2000)

All in all, these changes threaten to 'end' a certain notion of professionalism, if we take that to involve Goodson and Hargreaves' seven principles: discretionary judgement, moral engagement, collaboration, heteronomy, care, continuous learning and complexity (1996: 20-1). Perhaps the most decisive aspect of current 'economies of performance' is their threatened elimination of a moral landscape featuring notions like autonomy and trust (Dawson 1994; Bell 1995; Strathern 2000; Lambek 2000; Day 2000), particularly perhaps in the removal of just those elements of risk in professional performance on which opportunities for trust need to be built - Lyons and Mehta call it 'goodwill trust' (1997: 242). Similarly, the notion of professionalism inherently charged with accounting for itself is displaced (Ryan 1996; Lambek 2000). Again, as Strathern has pointed out, audit, policy and ethics become constitutive of each other, a 'triad of emergent practices' (Strathern 2000: 282), and the professional 'self' emerges as an contradictory effect rather than an agent within the audit culture.

So is there no room for hope? Possibly not. But in this version of our 'conclusion' we choose to round up as many optimistic indicators as we can muster - after all, they are our only hope of a politics that is for professionalism as well as about professionalism. What are the grounds for hope? First, the tension between 'economy' and 'ecology' is irresolvable, an immanent and necessary conflict. Such tension makes professionalism an issue for itself that will not go away. Second, professional discourses seem increasingly to be colonised from without - by managers, policy-makers and media. Yet such colonisation cannot avoid critique. 
That critique is, and must be, constitutive of new selves. Such identity formation develops as a 'narrative ethic' (Mieth 2000: 20). Professionals must re-story themselves in and against the audit culture. Further, the current 'economy of performance' in education at least is based on an obvious fantasy of economic and professional order. It is easily mocked. Such 'effectiveness' discourses are vulnerable to the Hegelian criticism that institutions turn against themselves 'if they are allowed to follow their own autonomous logic of existence' (Miller 1998: 202). Their logic is universalist prescription for 'professional performances' which cumulate into an absurdity that can readily be demonstrated. In any case, as Bernstein points out:

'There is a paradox at the heart of symbolic control. Control cannot control itself, any more than discourse can control discourse. Symbolic control, always a condition for someone else's order, carries within itself the potential for transforming the order of the imposing other' (1990: 159).

These dilemmas and contradictions sustain 'professionalism' in crisis, as a recurrent problem subject to somewhat repetitive sets of 'reforms' and 'improvements', none of which really work because they obscure rather than address the problems whose symptoms they are forced to dissemble or at least disguise. Thus the 'symbolic hybrid' of the professional hero or heroine (Larson 1990: 44) - whether utopian or nostalgic in its appeal - is ripe for 'sceptical denunciation' (ibid:45). Such a critique will not restore the 'professional' to the mythic status he or she never quite achieved, but it may allow new narrative ethics to develop via a 'restoration of trust' (Ryan 1996:640; Meith 2000). After all, deficit models of evaluation, such as those promoted within the audit culture are eventually demotivational in their effects, and hence exposed to mounting criticism.

For all these reasons, the current situation is probably highly unstable for both sets of professionals. In addition, our professionals were well aware of the pernicious differences between the 'paper' and the 'real' in their institutions, and so critique can have a fertile base in solidarity and opposition. An 'emergent ethics' based on 'negotiation' rather than bureaucratic fiat is already on the agenda (Pels 2000: 163), and indeed Brown et al have recently called in passing for a 'counter-movement'. (2000: 469).

On these counts, we argue that current audit discourses are highly vulnerable, and have predicted elsewhere (Stark et al 2000) that a 'turnover' is imminent. Policies cannot indefinitely accumulate illogics and contradictions. Morale cannot decline for ever without impacting on recruitment, retention and commitment. One conclusion is that the nature of the current 'economy of performance' and its corrosive relation with ecologies of practice offer to professionals such an impoverished intellectual and practical diet that professional lives cannot be sustained.

'...lean meat requires more calories to digest than it supplies, a point illustrated by what the explorer Henry Stanley called in 1890 the "starvation camps" in the middle of the Ituri: people were dying while surrounded by game' (Hart and Hart 1996: 55)

Professionalism, then, cannot thrive on performance indicators. It has, in the end, to rely on positive trust rather than be driven by performance ranking. If professionalism is to be 'risked' once more, such a risk will involve re-negotiating an economy of performance from within professional ecologies of practice. Our optimistic hypothesis would argue that policy-makers, in particular, need to understand professional performances very differently. Perhaps we should tell them that the metaphor for 
professionalism is 'pulse' rather than 'push'. The teleology of the utopian professional self, and the ontology of the vocationally oriented human being operate in a pulselike way. Each professional performance - whether it succeeds or fails - articulates some version of that 'pulse'. It may be pathological: practice is poor, or too urgent to be planned optimally, or too poorly resourced to be effective, but each moment of practice articulates an accommodation between the actual and the ideal, the possible and the desirable - as the nurse or teacher sees it. If we are to get real about professionalism we need therefore to appreciate that professionals do not conduct their practices in the 'real' so much as they traffic between the twin abstractions of the ideal (fed by both teleological and ontological strands) and the unrealised. Practice, in this account, is abstraction's residue. Such a 'pulse' (inside-out, at heart) needs to be encouraged, developed, rewarded (outside-in, and then inside-out). To be healthy, it needs exercise rather than medication, for it is not prefaced on a deficit model. And it needs a simple recognition: excellence can only be motivated, it cannot be coerced.

\section{References}

Aikens M P (1997) 'Evidence-based care: a new paradigm for clinical practice', Journal of Nurse-Midwifery 42, 1: 1 - 3

Apple M (1992) Teachers and texts: a political economy of class and gender relations in education. New York: Routledge

Ball S, Goodson I (1985) Teachers' lives and careers London: Falmer

Ball $\mathrm{J}$ (1999) 'Global trends in educational reform and the struggle for the soul of the teacher' British Educational Research Association Conference, Sussex, September

Barker $P$ (1998) 'The future of interprofessional relations? a personal reflection on Peplau's legacy' Journal of Psychiatric and Mental Health Nursing, 5, 213-220

Bauer R (1996) 'Professional ethics and the concept of the "merits"' Journal of Applied Philosophy 13, 1: $21-30$

Beck J (1999) 'Makeover or takeover? The strange death of educational autonomy in neo-liberal England' British Journal of Sociology of Education 20, 2: 223 - 238

Bell J (ed)(1995) Teachers talk about teaching. Coping with change in turbulent times. Buckingham, Open University Press

Benner P (1984) From novice to expert: excellence and power in clinical nursing practice. Menlo Park, Calif.: Addison-Wesley

Bennett J (1993) Human ecology as human behavior. Essays in environmental and developmental anthropology New Brunswick: Transaction Publishers

Bernstein B (1990) The structuring of pedagogical discourse. Volume 4. Class, codes and control. London: Routledge

Bertillson M (1990) 'The welfare state, the professions and citizens' in Torstendhal R, Biott C Edwards S \& Easen P (1997) 'Reflective Practice in multiprofessional contexts: visibility, culture and structures'. Paper presented at the British Education Research Association conference, York, September 
Bottery M, Wright N (1996) 'Cooperating in their own deprofessionalisation? On the need to recognise the "public" and "ecological" roles of the teaching profession' British Journal of Educational Studies 4, 44: 82 - 98

Bronfenbrenner $U$ (1986) 'Ecology of the family as a context for human development: research perspectives' Developmental Psychology 22, 6: 723 - 742

Biott C, Rauch F (1990) 'Preparing for external inspection. School leadership as a continuing project in identity construction', in Day C et al (eds) (op cit)

Bowers C, Flinders D (1990) Responsive teaching. An ecological approach to classroom patterns of language, culture and thought New York: Teachers College Press

Breinlinger S, Kelly C (1994) 'Women's responses to status inequality: a test of social identity theory' Psychology of Women Quarterly 18: 1 - 16

Brown M, Millett A, Bibby T, Johnson D (2000) 'Turning our attention from the what to the how: the national numeracy strategy' British Journal of Educational Research 26, 4: $457-471$

Bullough R, Knowles J G, Crow N (1991) Emerging as a teacher London: Routledge Campbell R, Neill S (1994) Primary teachers at work London: Routledge

Cant S, Sharma $U$ 'Reflexivity, ethnography and the professions (complementary medicine). Watching you watching me watching you (and writing about both of us)' Sociological Review 46, 2: $244-263$

Calderhead J (1987) (ed.) Exploring teachers' thinking. London: Cassells

Carrier J, Miller D (1998) (eds) Virtualities. A new political economy. Oxford: Berg

Chinn K Jacobs M (1987) Theory and nursing - a systematic approach. 2nd edition, Mosby, St. Louis

Clandinin J, Kennedy M, La Rocque L, Pearce M (1996) 'Living the tension: a case study of teacher stories of teacher evaluation' Journal of Education Policy 11, 2: 169 $-183$

Clandinin J, Connelly M (1996) 'A storied landscape for teacher knowledge', in Kompf et al (eds) (op cit)

Dawson A (1994) 'Professional codes of practice and ethical conduct' Journal of Applied Philosophy 11,2:145-153

Dawson P (1998) 'The self' in Edwards S (ed.) Philosophical issues in nursing. London: Routledge

Day C, Hadfield M (1996) 'Metaphors for movement: accounts of professional development' in Kompf et al (eds) (op cit)

Day C, Fernandez A, Hauge T, Moller J (2000) The life and work of teachers.

International perspectives in changing times. London: Falmer 
Day C (2000) 'Effective leadership and reflective practice' Reflective Practice 1, 1: $113-127$

Department of Health (DoH) (1999) Making a difference. Strengthening the nursing, midwifery and health visiting contribution to health and healthcare. London

Dingwall R, Mclntosh J (1978) Readings on the sociology of nursing London: Churchill Livingstone

English National Board (ENB) (1999) The acquisition of key skills for mental health nursing practice. London, April

Eraut M, Alderton J, Boylan A, Wraight A (1995) Learning to use scientific knowledge in education and practice settings: an evaluation of the contribution of the biological, behavioural and social sciences to pre-registration nursing and midwifery programmes. London: ENB

Erikson E (1982) 'The life cycle completed' in Leddy S, Pepper J (eds) (op cit)

Etzioni A (ed.)(1969) The semi-professions and their organization. Teachers, nurses, social workers New York: Free Press

Falk P (1988) 'The past to come' Economy and Society 17, 3: $244-251$

Fine B (1998) 'The triumph of economics: or, "rationality" can be dangerous to your reasoning' in Carrier J, Miller D (eds) (op cit)

Friedson $E$ (1983) 'The theory of professions: the state of the art' in Dingwall $R$, Lewis P (eds) The sociology of professions London: Macmillan

Galton M, Hargreaves L, Wall D (1999) Inside the primary classroom: 20 years on. London: Routledge

Ginsburg M (1996) 'Professionalism or politics as a model for educators' engagement with/in communities' Politics of Educational Association Yearbook: 5 - 12

Giri A (2000) 'Audited accountability and the imperative of responsibility. Beyond the primacy of the political', in Strathern, M (ed.)(op cit)

Gluckman M (1963) Order and rebellion in tribal Africa. Collected essays. London: Cohen and West

Goffman E (1961) Asylums: essays on the social situation of mental patients and other inmates. Harmondsworth: Penguin

Goodson I (2000) 'Professional knowledge and the teachers' life and work' in Day C et al (eds) (op cit)

Gottlieb E (1996) 'Mapping the utopia of professionalism: the First Carnegie International Survey of the academic profession', in Paulston R (ed) (op cit)

Gouldner A (1957) 'Cosmopolitans and locals: towards an analysis of latent social roles' Administrative Science Quarterly 2: 282 - 303 
Hargreaves A, Goodson I (1996) 'Teachers' professional lives: aspirations and actualities' in Hargreaves A, Goodson I (eds) Teachers' professional lives London: Falmer

Hargreaves D (1996) 'Teaching as a research-based profession: possibilities and prospects. London: Teacher Training Agency Annual Lecture

Harris A, Bennett N, Preedy M (eds)(1997) Organizational effectiveness and improvement in education Buckingham: Open University Press

Harrison S (1995) 'Four types of symbolic conflict' Journal of Royal Anthropological Institute 1: $255-272$

Hart T, Hart J (1996) The ecological basis of hunter-gatherer subsistence in African rain forests, in (eds) Bates, D, Lees S Case studies in human ecology New York: Plenum Press

Haughey M, Howard P, Marshall S (1996) 'Technical expertise and teacher growth: results of a teacher evaluation policy impact study' Journal of Education Policy 11, 2: $159-168$

Helgason A. Palsson G (1997)'Contested commodities: the moral landscape of modernist regimes' Journal of the Royal Anthropological Institute (N.S) 3: $451-471$

Helsby G (1990) 'Multiple truths and contested realities. The changing faces of teacher professionalism in England', in Day C et al (eds) (op cit)

Hoyle E (1980) 'Professionalization and deprofessionalization in education' in Hoyle E, Megarry J (eds) World yearbook of education: 1980: the professional development of teachers London: Kogan Page

Humphreys J (2000) 'Education and the professionalization of nursing: non-collective action and the erosion of the labour-market control' Journal of Education Policy 15, 3: $263-279$

Jameson F (1983) 'Postmodernism: the cultural logic of late capitalism' New Left Review 146: $15-67$

Jamous H, Peloille B (1970) 'Professions or self-perpetuating systems' in Jackson J (ed.) Professions and professionalization Cambridge: Cambridge University Press

Katz F (1969) 'Nurses', in Etzioni, A (ed.) (op cit)

Keogh J (1997) 'Professionalisation of nursing: development, difficulties and solutions' Journal of Advanced Nursing 25: $302-302-308$

Kirby C (1995) The world of nursing. In Theory and practice of nursing. Basford $L$ and Slevin O (Eds). Edinburgh: Campion Press

Kompf M, Bond W, Dworet D, Boak R (eds)(1996) Changing research and practice: teachers' professionalism, identities and knowledge. London: Falmer

Kundera M (1991) Immortality (tr. P Kussi) London: Faber and Faber

Lambek M (2000) 'The anthropology of religion and the quarrel between poetry and philosophy' Current Anthropology 41, 3: $309-320$ 
Larson M (1990) 'In the matter of experts and professionals, or how impossible it is to leave nothing unsaid', in Torstendahl R, Burrage M (eds) (op cit)

Latour B (1990) 'Postmodern? No, simply modern! Steps towards an anthropology of science' Studies in the History and Philosophy of Science 21, 1:145-171

Lave J (1996) 'Teaching, as Learning, as Practice' Mind, Culture, and Activity 3, 3: $149-164$

Leddy S, Pepper J (1998) Conceptual bases of professional nursing. New York: Lippincot

Linn R (2000) 'Assessments and accountability' Educational Researcher 29, 2: 4 16

Liston D (2000) 'Love and despair in teaching' Educational Theory 50, 1: 81 - 102

Lortie D (1969) 'The balance of control and autonomy in elementary school teaching', in Etzioni A (ed.) (op cit)

Lyons B, Mehta J (1997) 'Contracts, opportunism and trust: self-interest and social orientation Cambridge Journal of Economics 21: 239 - 257

McCulloch G (1990) 'The politics of the secret garden', in Day C et al (eds) (op cit) Mackintosh M (2000) 'Flexible contracting? Economic cultures and implicit contracts in social care' Journal of Social Policy 29, 1: 1-19

Measor L (1985) 'Critical incidents in the classroom' in Ball S, Goodson I (op cit)

Mieth D (2000) 'Moral identity. How is it narrated?' in Haring H, Junker-Kenny M,

Mieth D (eds) Creating Identity. Concilium 2000, 2. London: SCM Press

Miller D (1998) 'Conclusion: a theory of virtualism' in Carrier J, Miller D (eds) Virtualism. A new political economy. Oxford: Berg

Murphy R (1990) 'Proletarianism or bureaucratisation: the fall of the professional', in Torstendahl R, Burrage M (eds) (op cit)

Neiburg F, Golman M (1998) 'Anthropology and politics in studies of national character' Cultural Anthropology 13, 1: $56-81$

Ohlen J, Segesten K (1998) 'The professional identity of the nurse: concept analysis and development' Journal of Advanced Nursing 28, 4: 720 - 727

Parkin P (1995) 'Nursing the future: a re-examination of the professionalization thesis in the light of some recent developments' Journal of Advanced Nursing 21: 561 - 567

Paulston R (ed) (1996) Social cartography. Mapping ways of seeing social and educational change New York: Garland Publishing

Pels P (1999) 'Professions of duplexity. A prehistory of ethical codes in anthropology' Current Anthropology 40, 2: 101 - 136 
Pels P (2000) 'The trickster's dilemma. Ethics and the technologies of the anthropological self', in Strathern, M (ed.) (op cit)

Pirrie A (1999) 'Rocky mountains and tired Indians: on territories and tribes. Reflections on multidisciplinary education in the health professions' British Educational Research Journal 25, 1: 113 - 126

Power M (1994) The audit explosion London: Demos

Rappaport J 'In praise of paradox: a social policy of empowerment over prevention' American Journal of Community Psychology 9: 1 - 25

Redman R (1997) 'The entrepreneurial nurse: new opportunities and challenges' in Moorhead S, Gardner Huber D (eds) Nursing roles. Evolving or recycled? London: Sage

Reynolds D (1998) 'Teacher effectiveness: better teachers, better schools' Teacher Training Agency Corporate Plan Launch 1998 - 2001, London, TTA.

Rolfe G (1998) 'The theory practice gap in nursing: from research based practice to practitioner based research' Journal of Advanced Nursing 28, 3: $672-679$

Rutty J (1998) 'The nature of philosophy of science, theory and knowledge relating to nursing and professionalism' Journal of Advanced Nursing 28, 2: $243-250$

Ryan A (1996) ‘Professional liars’ Social Research 63, 3: 619 - 641

Scott C (1998) 'Specialist practice: advancing the profession?' Journal of Advanced Nursing 28, 3: 554 - 563 Sarvimani A (1988) 'Nursing as a moral, practical, communicative and creative activity' Journal of Advanced Nursing 13, 4: 462 - 467

Salvage J (1995) 'What's happening to nursing?' British Medical Journal 311: 274 275

Sarvimaki A (1988) 'Nursing as a moral practical, communicative and creative practice'. Journal of Advanced Nursing 13(4) 462-467

Shain F, Gleeson D (1999) 'Under new management: changing conceptualisations of teacher professionalism and policy in the further education sector Journal of Education Policy 14, 4: 445 - 462

Shore C, Wright S (2000) 'Coercive accountability. The rise of audit culture in higher education', in Strathern (ed.) (op cit)

Sikes P (1985) 'The life cycle of the teacher' in Ball S, Goodson I (eds) (op cit)

Smith J (1981) Nursing science in nursing practice. London: Butterworth

Smith M (1999) 'Caring and the science of unitary beings' Advances in Nursing Science, 4, 21: $14-28$

Sokefeld M (1999) 'Debating self, identity and culture in anthropology' Current Anthropology 4, 40: 417 - 446 
Stark S, Stronach I, Warne T (2000) 'Mental health teamworking: zones of comfort and challenge' Keynote speech to the ENB Mental Health conference, Robinson College, Cambridge, July

Stark S, Stronach I, Warne T, Skidmore D, Montgomery M (2000) Educational Preparation for mental health nursing: outcomes evaluation of the contribution of mental health nurses within multi-professional multi-agency teams. Final Report to the ENB, Manchester Metropolitan University, June

Strasen L (1992) The image of professional nursing: strategies for action. Phil., Mass.: Lippincott

Strathern M (1996) 'Cutting the network' Journal of Royal Anthropological Institute (N.S.) 2: $517-535$

Strathern M (2000) 'The tyranny of transparency' British Educational Research Journal 26, 3: 309 - 321

Strathern M (ed) (2000) Audit cultures. Anthropological studies in accountability, ethics and the academy. London: Routledge

Strauss C (1997) 'Partly fragmented, partly integrated: an anthropological examination of "postmodern fragmented subjects"' Cultural Anthropology 12, 3: 362 404

Stronach I, Cope P, Inglis B, McNally J (1994) 'The SOED "Competence” guidelines for ITT: issues of control, performance and relevance' Scottish Educational Review 26, 2: $118-133$

Stronach I, MacLure M (1997) Educational Research Undone. The postmodern embrace Buckingham: Open University Press

Stronach I (1997) 'Evaluation with the lights out. Deconstructing illuminative evaluation and new paradigm research' in Mabry L (ed.) Advances in program evaluation (vol. 3). Evaluation and the postmodern dilemma Greenwich, Conn.: JAI Press

Stronach I (1999) 'Shouting theatre in a crowded fire: "Educational Effectiveness" as cultural performance' Evaluation 5,2: 173 - 193

Stronach I 'Quality is the key, but is education the lock? Turning education around through quality procedures' in Stronach I (ed.) Proceedings of the Ways towards Quality in Education International Conference. Open Society/ Sola na Ravanatelje, Brdo, Slovenia, May

Torstendahl R, Burrage M (eds) (1990) The formation of professions. Knowledge, state and strategy. London: Sage

Troman G (1996) 'The rise of the new professionals? The restructuring of primary teachers' work and professionalism' British Journal of Sociology of Education 17, 4: $473-487$

Turner B (1993) 'Talcott Parsons, universalism and the educational revolution: democracy versus professionalism' British Journal of Sociology 44, 1: 1 -24 
Vollmer H, Mills D (eds) (1966) Professionalization. New Jersey, Prentice Hall

Waller W (1974) The sociology of teaching (8th edition, first published 1932) New York: John Wiley \& Sons

Woods P et al (1997) Review symposium. 'Restructuring schools, reconstructing teachers: responding to changes in the primary school' British Journal of Sociology of Education 19, 3: $419-431$

UKCC (1999) Fitness for practice. The UKCC Commission for nursing and midwifery. London, September

Wilmott R (1999) 'Structure, agency and the sociology of education: rescuing analytical dualism' British Journal of Sociology of Education 20, 1: 5 - 21

Wilmott $R(2000)$ 'The place of culture in organisation theory: introducing the morphogenetic approach' Organization 7, 1, 2000: 95 - 128

Wragg E (1993) Primary teaching skills London: Routledge

\section{Appendix A}

\section{Acronyms}

DfEE Department for IEducation and Employment

ENB English National Board for Nursing, Midwifery and Health Visiting

MHN Mental Health Nurse

NNS National Numeracy Strategy

OFSTED National Inspection Agency for schools (in England and Wales)

SATs Standard Attainment Tasks

TIMSS Third International Mathematic and Science Survey 